\begin{tabular}{|l|l|}
\hline Postprint Version & 1.0 \\
\hline Journal website & $\underline{\text { http://linkinghub.elsevier.com/retrieve/pii/S0895-4356(11)00092-8 }}$ \\
\hline Pubmed link & $\underline{\text { http://www.ncbi.nlm.nih.gov/pubmed?term }=21689904}$ \\
\hline DOI & $10.1016 /$ j.jclinepi.2011.03.006 \\
\hline
\end{tabular}

This is a NIVEL certified Post Print, more info at http://www.nivel.eu

\title{
Nijmegen Continuity Questionnaire: Development and testing of a questionnaire that measures continuity of care
}

\author{
ANNEMARIE A. UiJeN ${ }^{\mathrm{A}}$, , FranÇOIS G. SCHELlEVis ${ }^{\mathrm{B}}$, C, WIL J.H.M. VAN DEN BOSCH ${ }^{\mathrm{A}}$, HeNK G.A. \\ MOKKINK $^{\mathrm{A}}$, CHRIS VAN WEEL ${ }^{\mathrm{A}}$, HENK J. SCHERS ${ }^{\mathrm{A}}$ \\ ${ }^{a}$ Department of Primary and Community Care, Radboud University Nijmegen Medical Centre, 117, PO Box \\ 9101, 6500 HB, Nijmegen, The Netherlands \\ ${ }^{b}$ Netherlands Institute for Health Services Research (NIVEL), Utrecht, The Netherlands \\ ${ }^{c}$ Department of General Practice/EMGO Institute VU University Medical Centre, Amsterdam, The \\ Netherlands
}

\begin{abstract}
Objective: To develop and pilot test a generic questionnaire to measure continuity of care from the patient's perspective across primary and secondary care settings.

Study Design and Setting: We developed the Nijmegen Continuity Questionnaire (NCQ) based on a systematic literature review and analysis of 30 patient interviews. The questionnaire consisted of 16 items about the patient-provider relationship to be answered for five different care providers and 14 items each on the collaboration between four groups of care providers. The questionnaire was distributed among patients with a chronic disease recruited from general practice. We used principal component analysis (PCA) to identify subscales. We refined the factors by excluding several items, for example, items with a high missing rate.

Results: In total, 288 patients filled out the questionnaire (response rate, 72\%). PCA yielded three subscales: "personal continuity: care provider knows me," "personal continuity: care provider shows commitment," and "team/cross-boundary continuity." Internal consistency of the subscales ranged from 0.82 to 0.89 . Interscale correlations varied between 0.42 and 0.61 .

Conclusion: The NCQ shows to be a comprehensive, reliable, and valid instrument. Further testing of reliability, construct validity, and responsiveness is needed before the NCQ can be more widely implemented.
\end{abstract}

\section{INTRODUCTION}

\section{What is new?}

- We developed a generic questionnaire to measure continuity of care from the patient's perspective in primary and secondary care settings.

- Initial testing of this questionnaire shows it to be a comprehensive, reliable, and valid instrument.

- This is the first instrument that - regardless of morbidity and across multiple care settingsmeasures patients' experienced continuity of care as a multidimensional concept, that is, having a personal care provider and communication/cooperation between care providers.

- This is a promising questionnaire to identify problems and evaluate interventions aimed at improving continuity of care and to enable us to compare continuity experiences for different diseases and multimorbidity patterns. 
Continuity of care is an important aspect of patient care. Having a personal care provider (personal continuity) is related to better health [1], more confidence in the care provider [2] and [3], more patient satisfaction [3], [4] and [5], higher quality of patients' life [6] and [7], and less health care costs [8] and [9]. Over time, many instruments have been developed to measure personal continuity [10].

However, because of recent developments in health care, the concept of continuity of care has changed [11], [12] and [13]. With more subspecialization, fragmentation of health care, part-time practice, and an increase in the number of patients with multiple chronic diseases, an increasing number of care providers are involved in the care of patients. Continuity of care is nowadays considered a multidimensional concept, including not only personal or relational continuity but also informational continuity and team/crossboundary continuity requiring communication and collaboration between care providers [11], [12] and [13] . Some instruments have been developed to measure continuity of care as a multidimensional concept, but they all focus solely on a single disease [14], [15] and [16]. Such measurement instruments do not take into account that continuity is particularly important in situations where multimorbidity exists [17].

Moreover, most existing instruments are developed to measure continuity of care in one care setting, for example, in primary care, whereas a substantial number of chronic patients also contact medical specialists in the hospital or in an outpatient department.

At last, some instruments measure continuity of care from the provider's perspective or by using medical records, whereas we believe that continuity of care should be measured from the patient's perspective [18]. To our knowledge, there is no instrument available yet that measures patients' experienced continuity of care as a multidimensional concept regardless of morbidity and across multiple care settings. Such a measurement instrument would allow us to identify problems and evaluate interventions aimed at improving continuity of care. Moreover, it would enable us to compare continuity experiences for different diseases and multimorbidity patterns.

The aim of this study is, therefore, to develop and pilot test a generic questionnaire to measure continuity of care from the patient's perspective as a multidimensional concept and across multiple care settings.

\section{METHODS}

\subsection{Development: item generation}

We performed a systematic literature review of articles describing measurement instruments for continuity of care. We searched PubMed for articles focusing on continuity of care or related concepts, such as coordination or integration of care published from January 1997 to January 2007. We also searched in the reference list of all included articles and screened articles about continuity of care from our own database on continuity. We included all articles describing or using measurement instruments that included items about having a personal care provider and/or communication or cooperation between care providers (see Box 1). We screened 3,152 articles and finally included and analyzed 83 articles in which 82 different measurement instruments are described (search strategy and list of articles and instruments available on request). None of these 82 instruments measured patients' experienced continuity of care as a multidimensional concept regardless of morbidity and across multiple care settings.

\section{[Box 1.]}

We generated items for our questionnaire by including all items measuring aspects of the key domains of interest (Box 1) from the 82 identified instruments. We merged items with exactly the same content by using formulations that we think are easiest to understand and fit the Dutch situation.

In addition, we analyzed 30 patient interviews that were conducted as part of a study on continuity of care for additional items [19].

This resulted in a draft questionnaire (Nijmegen Continuity Questionnaire [NCQ]), including 20 general items (about types of care providers seen, age, sex, ethnicity, etc) and 136 items about continuity (16 items about the patient-provider relationship to be answered for five different care providers ( 80 items): most important care provider in general practice, other care provider in general practice, most important care provider in hospital/outpatient department, other care provider in hospital/outpatient department, and care 
provider outside general practice and hospital/outpatient department, and 14 items on the collaboration between four groups of care providers ( 56 items): between care providers within general practice, between care providers within the hospital/outpatient department, between general practice and hospital/outpatient department, and between general practice and care providers outside general practice and hospital/outpatient department). The items on continuity were rated according to a five-point Likert scale ranging from 1 (strongly disagree) to 5 (strongly agree), with an additional option to choose "?" ("I do not know"). Some items were negatively worded to reduce bias.

\subsection{Validity: face validity and reading level}

Subsequently, we tested face validity by interviewing 15 patients with chronic diseases (varying in age, number of chronic diseases, number of care providers seen, and type of general practice in which they were listed) according to the "thinking aloud technique" [20]. Patients were asked to think aloud when they answered each question. Interviews were audiotaped, and the interviewer wrote down verbal and nonverbal reactions indicating difficulties in instruction and item wording. Difficulties were corrected and tested in subsequent interviews. After 13 patients no new difficulties in the questionnaire were identified; therefore, we assumed that data saturation was achieved after 15 interviews, which corresponds to the description of Streiner and Norman [20]. Finally, the questionnaire included 136 items on continuity and 21 general items. The reading level of the NCQ was then assessed according to the Flesch-Kincaid grade level [21].

\subsection{Pilot testing: participants}

In January 2009, 31 general practitioner (GP) trainees working in practices in the eastern part of the Netherlands were asked to distribute 25 questionnaires each to patients with one or more chronic diseases. For these patients, continuity is particularly important, and most of them would have contacted a medical specialist in the hospital/outpatient department in the previous year. We excluded patients under the age of 18 years or who were unable to speak or read Dutch. Patients filled out the NCQ at home and could send it back directly to the researchers. The GP trainees registered age, sex, and type of chronic disease(s) of all participating patients and filled out some questions about the type of practice they worked in. In the Netherlands, every patient is enlisted with one GP. The GP functions as a gatekeeper for specialist care.

\subsection{Analysis}

We used SPSS version 16.0 (SPSS Inc., Chicago, IL, USA) to analyze the data. We assessed item completion rates, means, standard deviation (SD), and percentage respondents with the highest and lowest score per item (ceiling and floor effect). We treated the items as continuous variables. Principal component analysis (PCA) was used to identify subscales. We performed PCA on 16 items about the patient-provider relationship across multiple care settings and per care setting separately. In the first analysis, several observations from one patient are included (e.g., observations from the care provider in general practice and hospital/outpatient department), whereas in the second analysis, the observations are all independent. We also performed PCA on 14 items about the collaboration and information exchange between the groups of care providers across multiple care settings and per care setting separately. We compared varimax rotation with direct oblimin rotation and finally chose the rotation that resulted in factors with the highest interpretability. We retained the factors with eigenvalues greater than 1 . We refined the factors by excluding items for several reasons: we excluded items that decreased the interpretability of the factor, had a relatively high rate of missing values, were relatively highly correlated to other items, had a relatively low $\mathrm{SD}$, had a relatively high floor or ceiling effect, loaded high on two factors or loaded low on all factors. Reliability of the subscales was assessed using Cronbach $\alpha$. We excluded items until Cronbach $\alpha$ was $<0.90$ to avoid item redundancy. For preliminary validation of the subscales, we assessed the mean, SD, and mean interitem correlations of the subscales and calculated Pearson correlations between the subscales.

\section{RESULTS}

\subsection{Reading level}

The estimated reading level was seven, indicating that respondents would need a seventh-grade education to understand the questionnaire [21]. The seventh grade is the seventh school year after kindergarten.

Seventh graders are usually $12-13$ years old. 


\subsection{Questionnaire response}

In total, 24 GP trainees participated, and they asked 398 patients to fill out the questionnaire, of which 288 $(72 \%)$ were returned.

\subsection{Patient characteristics}

Table 1 shows patients' characteristics and their medical care. Responders and nonresponders did not differ in age $(P=0.77)$, number of chronic diseases $(P=0.19)$, and type of general practice they were listed in $(P=0.30)$. Responders were more likely to be males $(P=0.03)$.

\section{[TABLE 1.]}

Most patients perceived general practice or hospital/outpatient department as their most important site of care (74\% and $21 \%$, respectively) and their GP and medical specialist as their most important care provider at these sites (264 of 288 patients [91.6\%] and 177 of 179 patients [98.9\%], respectively). Therefore, in this article, we will focus on the patient-provider relationship of the most important care provider in general practice and hospital/outpatient department and on the collaboration and information exchange between care providers within general practice, between care providers within the hospital/outpatient department, and between general practice and hospital/outpatient department.

\subsection{Item analysis}

Table 2 shows item means, SDs, missing rates, and percentage of respondents with the lowest and highest scores (floor and ceiling effect). Most items were weakly to moderately negatively skewed. The items about the collaboration between care providers within the hospital/outpatient department and the collaboration between general practice and hospital/outpatient department showed highest missing rates (mean of $26.1 \%$ and $24.9 \%$, respectively).

\section{[TABLE 2. ]}

\subsection{Subscales}

Before we performed PCA, we excluded items 3 and 9 (about trust and relationship) because these items were not distinctive for measuring continuity of care. For example, we found that patients could be negative about the continuity of their specialist (according to the other items) but still reported to experience a lot of trust in this care provider. Item 3 also showed poor variability.

PCA showed that the negatively worded items (items 6, 13, 20, and 25) loaded on a separate factor, which we could not interpret well. We found that patients answered these items more frequently with extreme values (higher ceiling effect). Patients answered inconsistently when comparing the negatively worded items with the positively worded items, which was also shown in other research [22]. Therefore, we decided to exclude the negatively worded items.

We performed PCA on the remaining items 1-16 about the most important care provider across multiple care settings and per care setting separately. Table 3 shows the varimax-rotated factor loadings of this first analysis. It resulted in the same factors as the last analysis. We compared varimax rotation with direct oblimin rotation and found no difference in final results. Two factors were generated, both with an eigenvalue above 1: "personal continuity: care provider knows me" and "personal continuity: care provider shows commitment," explaining a total variance of $70.3 \%$.

\section{[TABLE 3. ]}

We also performed PCA on the remaining items 17-30 about the collaboration between the groups of care providers across multiple care settings and per care setting separately, which resulted in the same single factor ("team/cross-boundary continuity"). Table 3 shows the factor loadings of this first analysis. This factor explained $73.7 \%$ of total variance.

\subsection{Item reduction}

We refined the factors by excluding some items. Table 3 shows the items that we excluded with their reasons for exclusion. From the first factor, we successively excluded items 2, 10, and 4. After excluding these items, Cronbach $\alpha$ was still high (0.90) and, therefore, we excluded item 8 as well. Factor 1 finally 
consisted of items $1,5,7,11$, and 12 . We did not exclude items from the second factor because it included only three items (items 14, 15, and 16).

From the third factor, we successively excluded items 17, 19, 24, 30, 26, 21, and 29. After excluding these items, Cronbach $\alpha$ was still high (0.92) and, therefore, we excluded item 22 as well. Factor 3 finally consisted of items 18,23,27, and 28. The final version of the NCQ can be found in the Appendix (see the Appendix on the journal's Web site at www.elsevier.com).

\subsection{Reliability}

Table 4 shows the mean interitem correlations and Cronbach $\alpha$ for the subscales after item reduction, as well as their means and SDs. Mean interitem correlation of the subscales varied between $r=0.58$ and $r=$ 0.71 . Internal consistency (Cronbach $\alpha$ ) ranged from 0.82 to 0.89 .

\section{[TABLE 4 ]}

To assess the cohesiveness of the scale, correlations between the subscales were examined. The mean correlation between subscales "personal continuity: care provider knows me" and "personal continuity: care provider shows commitment" was $r=0.61$. The mean correlation between subscales "personal continuity: care provider knows me" and "team/cross-boundary continuity" was $r=0.42$. The mean correlation between subscales "personal continuity: care provider shows commitment" and "team/cross-boundary continuity" was $r=0.49$.

Because of the relatively high correlation between "personal continuity: care provider knows me" and "personal continuity: care provider shows commitment," we hypothesized that showing commitment is a cumulative quality of personal continuity. When care providers know their patients very well, they can either show or not show the cumulative quality commitment. However, care providers who do not know their patients very well will probably not show commitment. In other words, "knowing the patient well" is a prerequisite for "showing commitment." We found support for this hypothesis in our data. Of all patients who answered that their care provider knew them very well (mean score $<4$ ), 59\% answered that their care provider showed the cumulative quality commitment (mean score $\geq 4$ ), whereas $41 \%$ of patients answered that their care provider did not show this cumulative quality well. Of the patients that answered that their care provider did not know them very well, $82 \%$ also answered that this care provider did not show the cumulative quality commitment well.

\subsection{Construct validity}

The construct validity of the NCQ was partly supported by the results of the PCA. In accordance with the definition of continuity in the literature, both personal continuity and team/cross-boundary continuity were identified in our questionnaire. We did not find a differentiation between informational continuity and team/cross-boundary continuity. We found that personal continuity might be subclassified in "care provider knows me" and "care provider shows commitment."

Construct validity was further supported by the high internal consistency of the subscales. The moderate correlations between "personal continuity" and "team/cross-boundary continuity" provide evidence of good discriminant validity. The high correlation $(0.61)$ between "personal continuity: care provider knows me" and "personal continuity: care provider shows commitment" was expected because they both measure aspects of personal continuity.

\section{DisCUSSION}

Initial testing of the NCQ shows that it is a comprehensive, reliable, and valid generic instrument to measure patients' experiences of continuity of care as a multidimensional concept across multiple care settings. To our knowledge, this is the first generic questionnaire that measures continuity of care as a multidimensional concept from the patient's perspective regardless of care setting and morbidity. The NCQ allows us to identify problems and evaluate interventions aimed at improving continuity of care. Moreover, it will enable us to compare continuity experiences for different diseases and multimorbidity patterns.

The NCQ subscales reflect recent definitions of continuity of care [11], [12] and [13] . However, contrary to conceptual literature, patients did not differentiate between informational continuity and team/crossboundary continuity. Haggerty et al. [23] also found that these two dimensions are hard to differentiate for patients. Face and content validity of the NCQ are supported by the involvement of patients and the 
published literature in the development of the questionnaire. Readability, which was tested by interviewing patients and calculating the Flesch-Kincaid grade level, was good. The internal consistencies of the subscales and the interscale correlations provide evidence of a reliable and valid questionnaire with good discriminant abilities. The correlation between the subscales "personal continuity: care provider knows me" and "personal continuity: care provider shows commitment" was highest $(0.61)$. We found support for the hypothesis that "knowing the patient well" is a prerequisite for "showing commitment." Although this hypothesis is tested on the same data as it is based on, we think that patients are able to differentiate between "care provider knows me" and "care provider shows commitment." Maintaining both these subscales will enrich the questionnaire and enable us to better differentiate personal continuity.

Further testing of reliability (test-retest), responsiveness, and construct validity against external criteria, such as satisfaction and confidence in care provider, is needed before the NCQ can be more widely implemented. The sample size and response rate of participants in this study were high, which strengthens our results and conclusions.

It is important to realize that this questionnaire measures continuity of care from the patient's perspective, which we believe it should be measured from [18]. Information from health records is not used in this measure. This makes it even more important to further test the reliability (test-retest).

\subsection{Item reduction}

Most patients perceived general practice or hospital/outpatient department as their most important site of care and their GP and specialist as their most important care provider at these sites. For future research, we decided, therefore, to reduce the items of the NCQ by focusing solely on the personal continuity provided by these care providers and on the team/cross-boundary continuity between these care providers (see the Appendix on the journal's Web site at www.elsevier.com). This shortens the questionnaire without losing important data, which will improve patients' motivation to fill out the questionnaire.

\subsection{Generalizability to other countries}

Our questionnaire is developed and tested in the Netherlands, a country where the GP has a gatekeeping role. This questionnaire is, therefore, easily applicable in other countries with the same care system, such as the United Kingdom. We think that our questionnaire is also useful in countries with a different care system. Possibly, the GP can be replaced by another care provider, which makes the questionnaire applicable to other care systems.

\subsection{Limitations}

One of the limitations of this study is that we solely recruited patients from general practice. Because most patients also contacted the hospital/outpatient department in the last year, we assume that our results are also applicable to patients recruited via the hospital/outpatient department. Further study is however needed to confirm this. Another limitation is that we solely included patients with a chronic disease, which lowers generalizability. However, continuity of care seems to be most important for patients with a chronic disease, and we do not think that our main results will differ substantially for patients without a chronic disease.

A last limitation is that most GP trainees approached less than 25 patients each. We do not have data of patients who met the inclusion criteria but who were not approached by the GP trainees. This may have resulted in a slight bias in the recruitment of participants. However, it is unlikely that this has influenced the factors identified in the PCA nor would it result in main differences in initial testing of reliability and construct validity. It may yield differences in individual experiences of continuity of care, but we did not aim to describe this.

\section{CONCLUSION}

This study provides initial evidence for the comprehensiveness, reliability, and validity of the NCQ as a generic questionnaire that measures continuity of care as a multidimensional concept from the patient's perspective across multiple care settings. Further testing of reliability (test-retest), construct validity, and responsiveness is needed before the NCQ can be more widely implemented. 
Uijen, A.A., Schellevis, F.G., Bosch, W.J.H.M. van den, Mokkink, H.G.A., Weel, C. van, Schers, H.J. Nijmegen Continuity Questionnaire: development and testing of a questionnaire that measures continuity of care Journal of Clinical Epidemiology: 2011, 64(12), 1391-1399

\section{REFERENCES}

[1] K.C. Stange and R.L. Ferrer, The paradox of primary care. Ann Fam Med, 7 (2009), pp. 293-299.

[2] K.S. Heller and M.Z. Solomon, Continuity of care and caring: what matters to parents of children with life-threatening conditions. J Pediatr Nurs, 20 (2005), pp. 335-346.

[3] H. Schers, H. van den Hoogen, H. Bor, R. Grol and W. van den Bosch, Familiarity with a GP and patients' evaluations of care. A cross-sectional study. Fam Pract, 22 (2005), pp. 15-19.

[4] P. Hjortdahl and E. Laerum, Continuity of care in general practice: effect on patient satisfaction. BMJ, 304 (1992), pp. 1287-1290.

[5] J.W. Saultz and W. Albedaiwi, Interpersonal continuity of care and patient satisfaction: a critical review. Ann Fam Med, 2 (2004), pp. 445-451.

[6] G. Freeman and P. Hjortdahl, What future for continuity of care in general practice?. BMJ, 314 (1997), pp. 1870-1873.

[7] J. Hanninen, J. Takala and S. Keinanen-Kiukaanniemi, Good continuity of care may improve quality of life in Type 2 diabetes. Diabetes Res Clin Pract, 51 (2001), pp. 21-27.

[8] M. Raddish, S.D. Horn and P.D. Sharkey, Continuity of care: is it cost effective?. Am J Manag Care, 5 (1999), pp. 727-734.

[9] L.J. Weiss and J. Blustein, Faithful patients: the effect of long-term physician-patient relationships on the costs and use of health care by older Americans. Am J Public Health, 86 (1996), pp. 1742-1747.

[10] S.H. Jee and M.D. Cabana, Indices for continuity of care: a systematic review of the literature. Med Care Res Rev, 63 (2006), pp. 158-188.

[11] M.H. Alazri, R.D. Neal, P. Heywood and B. Leese, Patients' experiences of continuity in the care of type 2 diabetes: a focus group study in primary care. Br J Gen Pract, 56 (2006), pp. 488-495.

[12] J.L. Haggerty, R.J. Reid, G.K. Freeman, B.H. Starfield, C.E. Adair and R. McKendry, Continuity of care: a multidisciplinary review. BMJ, 327 (2003), pp. 1219-1221.

[13] Reid R, Haggerty J, McKendry R. Defusing the confusion: concepts and measures of continuity of health care. University of Columbia, Prepared for the Canadian Health Services Research Foundation, the Canadian Institute for Health Information and the Advisory Committee on Health Services of the Federal/Provincial/Territorial Deputy Ministers of Health; 2002.

[14] L.R. Dolovich, K.M. Nair, D.K. Ciliska, H.N. Lee, S. Birch and A. Gafni, et al. The Diabetes Continuity of Care Scale: the development and initial evaluation of a questionnaire that measures continuity of care from the patient perspective. Health Soc Care Community, 12 (2004), pp. 475-487.

[15] M.C. Gulliford, S. Naithani and M. Morgan, Measuring continuity of care in diabetes mellitus: an experience-based measure. Ann Fam Med, 4 (2006), pp. 548-555.

[16] K.M. Kowalyk, H.D. Hadjistavropoulos and H.J. Biem, Measuring continuity of care for cardiac patients: development of a patient self-report questionnaire. Can J Cardiol, 20 (2004), pp. 205-212.

[17] N. Pandhi and J.W. Saultz, Patients' perceptions of interpersonal continuity of care. J Am Board Fam Med, 19 (2006), pp. 390-397.

[18] A.A. Uijen, H.J. Schers and C. van Weel, Continuity of care preferably measured from the patients' perspective. J Clin Epidemiol, 63 (2010), pp. 998-999.

[19] H.J. Schers, Continuity of care in general practice. Exploring the balance between personal and informational continuity, Radboud Universiteit, Nijmegen, The Netherlands (2004).

[20] D.L. Streiner and G.R. Norman, Health measurement scales. A practical guide to their development and use, Oxford University Press, Oxford (2008).

[21] D.B. Friedman and L. Hoffman-Goetz, A systematic review of readability and comprehension instruments used for print and web-based cancer information. Health Educ Behav, 33 (2006), pp. 352373.

[22] American Statistical Association. Negatively worded questions cause respondent confusion [report]; $2005 .$.

[23] Haggerty J, Beaulieu C, Roberge D, Freeman G, Fournier M, Mambu LM. A meta-summary of qualitative studies of patient perspectives of continuity of care from different care providers: identifying common themes for a generic measure of management continuity [data file]; $2008 .$.

APPENDIX SUPPLEMENTARY MATERIAL

Nijmegen Continuity Questionnaire. 
Appendix: Nijmegen Continuity Questionnaire (NCQ)

\section{Nijmegen Continuity Questionnaire}

\section{Questionnaire instructions}

We are interested in your experiences with the care providers that you contacted in the last 12 months.

This questionnaire includes 28 statements, and will take about 5-10 minutes to complete. There are no right or wrong answers. Your honest opinion is what counts.

For each statement, choose the answer that best describes your opinion.

All the information you provide will be kept completely confidential. Your answers will not be passed on to your care providers or others. 


\section{The following statements are about your (own) general practitioner}

If you did not contact a general practitioner in the last year, please go on to the next section.

$\begin{array}{llll}\begin{array}{l}\text { Strongly } \\ \text { agree }\end{array} & \text { Agree } & \text { Neutral Disagree } & \begin{array}{l}\text { Strongly } \\ \text { disagree }\end{array}\end{array}$

a I know my general practitioner very well

b My general practitioner knows my medical history very well

c My general practitioner always knows very well what he/she did previously

d My general practitioner knows my familial circumstances very well

e My general practitioner knows my daily activities very well

$f \quad$ My general practitioner contacts me if it is needed, I do not have to ask

g My general practitioner knows very well what I believe is important in my care

h My general practitioner keeps in contact sufficiently when I see other care providers 
2. The following statements are about the cooperation between care providers in general practice (e.g. between general practitioner and nurse practitioner or between several general practitioners).

If this section does not apply to you, please go on to the next section.

\begin{tabular}{lllll}
$\begin{array}{l}\text { Strongly } \\
\text { agree }\end{array}$ & Agree & Neutral & Disagree & $\begin{array}{l}\text { Strongly } \\
\text { disagree }\end{array}$ \\
\hline
\end{tabular}

a These care providers transfer information very well to each other

O $0 \quad 0 \quad 0 \quad 0$

b These care providers work together very well

c The care of these care providers is very well connected

d These care providers always know very well from each other what they do

\begin{tabular}{lllll|l|l}
0 & 0 & 0 & 0 & 0 & 0 \\
0 & 0 & 0 & 0 & 0 & 0 \\
0 & 0 & 0 & 0 & 0 & 0
\end{tabular}


3. The following statements are about your (most important) specialist

If you did not contact a specialist in the last year, please go on to the next section.

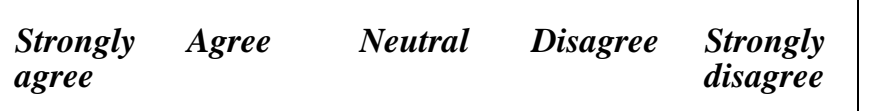

a I know this care provider very well

$0 \quad 0 \quad 0$

○

b This care provider knows my medical history very well

c This care provider always knows very well what he/she did previously

\section{$\bigcirc$}

$\bigcirc$

$\bigcirc$<smiles>O</smiles>

d This care provider knows my familial circumstances very well

O

O

$\bigcirc$

$\bigcirc$<smiles>O</smiles>

$\bigcirc$<smiles>[O]</smiles>

$\bigcirc$ daily activities very well

$f$ This care provider contacts me if it is needed, I do not have to ask

○

O

$\bigcirc$

(n)

g This care provider knows very well what I believe is important in my care

$\begin{array}{lllll}0 & 0 & 0 & 0 & 0 \\ 0 & 0 & 0 & 0 & 0\end{array}$

h This care provider keeps in contact sufficiently when I see other care providers 
4. The following statements are about the cooperation between care providers in hospital (e.g. between several specialists or between specialist and nurse)

If this section does not apply to you, please go on to the next section.

\begin{tabular}{llll|l}
$\begin{array}{l}\text { Strongly } \\
\text { agree }\end{array}$ & Agree & Neutral & Disagree & $\begin{array}{l}\text { Strongly } \\
\text { disagree }\end{array}$
\end{tabular} ?

a These care providers transfer

information very well to each other

$\bigcirc \quad 0 \quad 0$

$\bigcirc$

b These care providers work together very well

c The care of these care providers is very well connected

d These care providers always know very well from each other what they do

5. The following statements are about the cooperation between your general practitioner and your specialist.

If this section does not apply to you, than you finished the questionnaire.

Strongly Agree Neutral Disagree Strongly
agree disagree

a These care providers transfer information very well to each other

O $0 \quad 0$

$\bigcirc$

b These care providers work together very well

c The care of these care providers is very well connected

d These care providers always know very well from each other what they do 
Any comments/remarks:

Thank you for your help! 
Uijen, A.A., Schellevis, F.G., Bosch, W.J.H.M. van den, Mokkink, H.G.A., Weel, C. van, Schers, H.J. Nijmegen Continuity Questionnaire: development and testing of a questionnaire that measures continuity of care. Journal of Clinical Epidemiology: 2011, 64(12), 1391-1399

TABLES AND BOX

Box 1 Key domains of interest

\section{Personal care provider}

The patient has a personal care provider in every care setting with whom he/she can develop an ongoing relationship (personal/relational continuity).

\section{Communication and cooperation between care} providers

Care providers in the same care setting and between different care settings communicate and cooperate to connect their care in a coherent way. Care providers use information on past events to deliver care that is appropriate to the patient's current circumstances (informational/cross-boundary/management continuity). 
Uijen, A.A., Schellevis, F.G., Bosch, W.J.H.M. van den, Mokkink, H.G.A., Weel, C. van, Schers, H.J. Nijmegen Continuity Questionnaire: development and testing of a questionnaire that measures continuity of care. Journal of Clinical Epidemiology: 2011, 64(12), 1391-1399

Table 1. Characteristics and medical care of responders and nonresponders

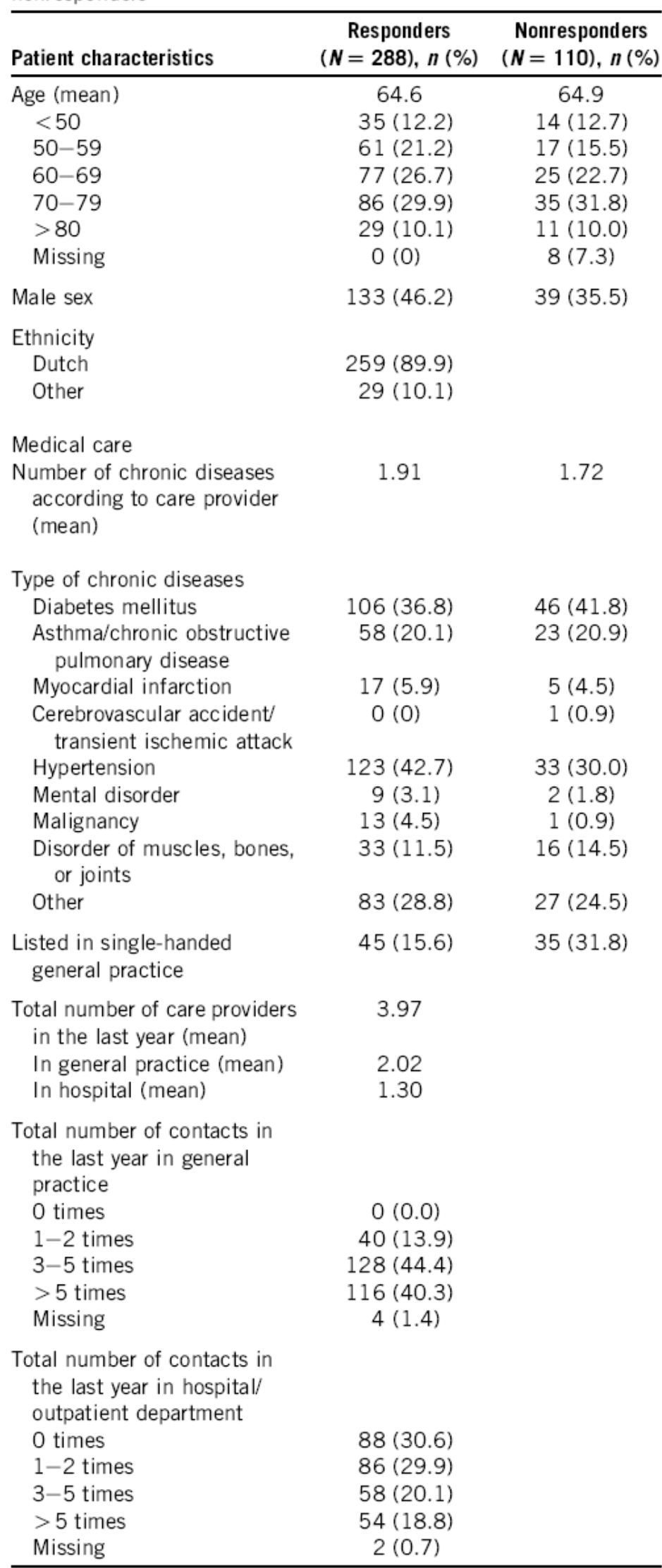

Values are in numbers (percentages) unless otherwise indicated. 
Table 2. Item means, SDs, missing rates, floor and ceiling effect

uestionnaire items
I know this care provider very well
This care provider knows me very well
I have a lot of trust in this care provider
This care provider knows very well which care I receive more
This care provider knows my medical history very well
I always have to repeat my story when I see this care provider again
This care provider always knows very well what helshe did previously
This care provider remembers me very well when he/she sees me
I have a very good relationship with this care provider
0. This care provider knows my relevant medical data very well
1. This care provider knows my familial circumstances very well
2. This care provider knows my daily activities very well
3. This care provider has always forgotten what I told before
4. This care provider contacts me if it is needed, I do not have to ask
5. This care provider knows very well what I believe is
important in my care
6. This care provider keeps in contact sufficiently when I see other
care providers

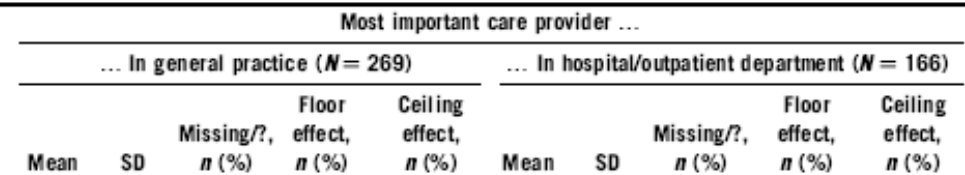

\begin{tabular}{|c|c|c|c|c|c|c|c|c|}
\hline Mean & SD & $\begin{array}{l}\text { Missing/7 } \\
n(\%)\end{array}$ & , effe & ffect, & $\begin{array}{l}\text { effe } \\
n \text { ( }\end{array}$ & & Mean & $s$ \\
\hline
\end{tabular}

$\begin{array}{lllllllllll}3.89 & 0.815 & 3(1.1) & 2(1.2) & 61(22.7) & 3.21 & 0.996 & 5(3.0) & 10(6.0) & 11(6.6)\end{array}$

$\begin{array}{llllllllll}3.92 & 0.786 & 5(1.9) & 2(1.2) & 60(22.3) & 3.24 & 1.025 & 6(3.6) & 11(6.6) & 12(7.2) \\ 4.13 & 0.702 & 5(1.9) & 0(0.0) & 79(29.4) & 4.02 & 0.635 & 4(2.4) & 0(0.0) & 32(19.3)\end{array}$

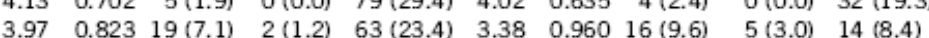

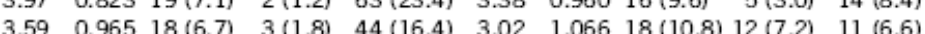

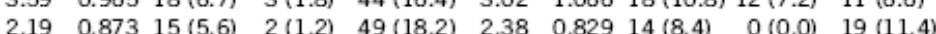

$\begin{array}{llllllllllll}3.51 & 0.917 & 17 & (6.3) & 3(1.8) & 32(1.9) & 3.26 & 0.937 & 19(11.4) & 5(3.0) & 8(4.8)\end{array}$

$\begin{array}{llllllllll}4.10 & 0.790 & 17(6.3) & 3(1.8) & 75(27.9) & 3.41 & 1.032 & 14(8.4) & 9(5.4) & 14(8.4)\end{array}$

$\begin{array}{lllllllllll}3.80 & 0.861 & 13(4.8) & 1(0.6) & 59(21.9) & 3.26 & 0.963 & 7(4.2) & 9(5.4) & 12(7.2)\end{array}$

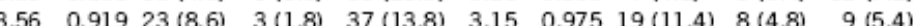

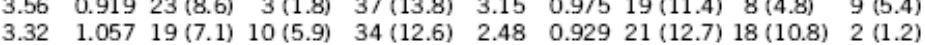

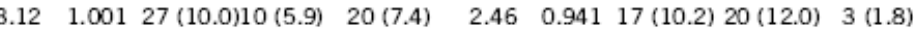

$\begin{array}{lllllllllll}1.97 & 0.789 & 21(7.8) & 4(2.4) & 65(24.2) & 2.42 & 0.819 & 19(11.4) & 0(0) & 18(10.8)\end{array}$

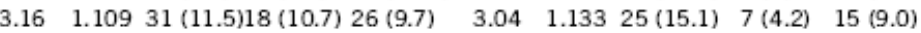

$\begin{array}{lllllllllll}3.53 & 0.873 & 26(9.7) & 7(4.1) & 22(8.2) & 3.21 & 0.975 & 17(10.2) & 6(3.6) & 9(5.4)\end{array}$

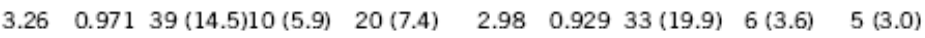

\begin{tabular}{|c|c|c|c|c|c|c|c|c|c|c|c|c|c|c|}
\hline \multicolumn{15}{|c|}{ Collaboration between care providers ... } \\
\hline \multicolumn{5}{|c|}{... Within general practice $(N=154)$} & \multicolumn{5}{|c|}{$\begin{array}{l}\ldots \text {. Within hospital/ } \\
\text { outpatient department }(N=77)\end{array}$} & \multicolumn{5}{|c|}{$\begin{array}{l}\text {.. In general practice and hospital/ } \\
\text { outpatient department }(N=152)\end{array}$} \\
\hline Mean & SD & $\begin{array}{l}\text { Missing/?, } \\
n(\%)\end{array}$ & $\begin{array}{l}\text { Floor } \\
\text { effect, } \\
n(\%)\end{array}$ & $\begin{array}{l}\text { Ceiling } \\
\text { effect, } \\
n(\%)\end{array}$ & Mean & SD & $\begin{array}{l}\text { Missing/?, } \\
n(\%)\end{array}$ & $\begin{array}{l}\text { Floor } \\
\text { effect, } \\
n(\%)\end{array}$ & $\begin{array}{l}\text { Ceiling } \\
\text { effect, } \\
n(\%)\end{array}$ & Mean & SD & $\begin{array}{l}\text { Missing??, } \\
\text { n (\%) }\end{array}$ & $\begin{array}{l}\text { Floor } \\
\text { effect, } \\
n(\%)\end{array}$ & $\begin{array}{l}\text { Ceiling } \\
\text { effect, } \\
n(\%)\end{array}$ \\
\hline 3.83 & 0.733 & $22(14.3)$ & $3(1.9)$ & $15(9.7)$ & 3.34 & 0.965 & $19(24.7)$ & $2(2.6)$ & $5(6.5)$ & 3.48 & 0.887 & $39(25.7)$ & $3(2.0)$ & $9(5.9)$ \\
\hline & & & & & & & & & & & & & & \\
\hline 3.80 & 0.751 & $24(15.6)$ & $3(1.9)$ & 15( & 3.28 & 0.978 & $20(26.0)$ & & & 3.50 & 0.821 & $24.3)$ & $1(0.7)$ & \\
\hline 1.99 & 0.722 & & $2(1.3)$ & & & 0.824 & & & & 2.19 & 0.765 & & $1(0.7) 1$ & \\
\hline 3.82 & 0.626 & & $1(0.6)$ & & & & & & & 3.46 & 0.723 & & $1(0.7)$ & \\
\hline 3.78 & 0.719 & $31(20.1)$ & $2(1.3)$ & 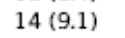 & 3.28 & 0.878 & $23(29.9)$ & $0(0.0)$ & $3(3$ & 3.39 & 0.893 & $43(28.3)$ & $2(1.3)$ & $6(3.9)$ \\
\hline 3.80 & 0.668 & & $1(0.6)$ & & & & & & & 3.39 & & & & \\
\hline 3.60 & 0.724 & $33(21$ & $1(0.6)$ & & & & & & & 44 & 0.737 & & & \\
\hline 2.64 & 0.988 & $13(8.4)$ & $2(1.3)$ & & & 0.941 & & 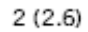 & & 2.70 & 0.971 & & $4(2.6)$ & \\
\hline 3.64 & 0.725 & & $2(1.3)$ & & & & & & & 3.35 & & & & \\
\hline 3.74 & 0.619 & & $1(0.6)$ & & 3. & & & & & 3.50 & 0.784 & $35(23.0)$ & $2(1.3)$ & \\
\hline 3.63 & 0.669 & & & $8(5.2)$ & 3.11 & 1.021 & $21(27.3)$ & $4(5$. & $3(3.9)$ & 3.25 & 0.841 & $47(30.9)$ & $2(1.3)$ & $4(2.6)$ \\
\hline & 0.653 & $26(16.9)$ & $1(0.6)$ & $8(5.2)$ & & & $23(29.9)$ & $4(5.2)$ & $5(6.5)$ & 3.45 & 0.808 & $42(27.6)$ & $2(1.3)$ & $5(3.3)$ \\
\hline
\end{tabular}

17. These care providers communicate very well with each other 18. These care providers transfer information very well to each other 19. The care of these care providers is very well adapted to each other

20. I often get contradictory information from these care providers

21. The care between these care providers goes very smoothly

22. These care providers are very well informed of each other

23. These care providers work together very well

24. These care providers always agree about the care I receive

25. I always have to tell my story again when I see the other care provider

26. These care providers are very involved in each other's ca

28. These care providers always know very well from each other what

they do

29. These care providers know the results of each other's medical

examination very well

\begin{tabular}{llllllllllllllll}
30 . These care providers know very well who else is concerned in my care & 3.55 & 0.764 & $33(21.4)$ & $1(0.6)$ & $10(6.5)$ & 3.04 & 1.098 & $23(29.9)$ & $6(7.8)$ & $3(3.9)$ & 3.22 & 0.872 & $45(29.6)$ & $3(2.0)$ & $4(2.6)$ \\
\hline
\end{tabular}

Mean score ( $1=$ strongly agree, $2=$ agree, $3=$ neutral, $4=$ disagree, and $5=$ strongly disagree).

Floor effect: number (percentage) of respondents with the lowest score. Ceiling effect: number (percentage) of respondents with the highest score.

Abbreviation: $\mathrm{SD}$, standard deviation. 
Uijen, A.A., Schellevis, F.G., Bosch, W.J.H.M. van den, Mokkink, H.G.A., Weel, C. van, Schers, H.J. Nijmegen Continuity Questionnaire: development and testing of a questionnaire that measures continuity of care Journal of Clinical Epidemiology: 2011, 64(12), 1391-1399

Table 3. Factor loadings and excluded items with their reasons for exclusion

\begin{tabular}{|c|c|c|c|c|c|}
\hline \multirow[b]{3}{*}{ Type of continuity } & \multicolumn{3}{|c|}{ Factor loadings } & \multirow[b]{3}{*}{$\begin{array}{l}\text { Excluded } \\
\text { items }\end{array}$} & \multirow[b]{3}{*}{ Reasons for exclusion } \\
\hline & Factor 1 & Factor 2 & Factor 3 & & \\
\hline & $\begin{array}{c}\text { Eigenvalue: } \\
7.304\end{array}$ & $\begin{array}{c}\text { Eigenvalue: } \\
1.130\end{array}$ & $\begin{array}{c}\text { Eigenvalue: } \\
8.617\end{array}$ & & \\
\hline \multicolumn{6}{|l|}{ PCA on items $1,2,4,5,7,8,10,11,12,14,15,16$} \\
\hline \multicolumn{6}{|l|}{ Personal continuity: care provider knows me } \\
\hline $\begin{array}{l}\text { 2. This care provider knows me very well } \\
(n=424)\end{array}$ & 0.880 & & & $\mathrm{x}$ & $\begin{array}{l}\text { Highly correlated to item } 1(0.924) \\
\text { but more difficult to answer }\end{array}$ \\
\hline 1. I know this care provider very well $(n=427)$ & 0.870 & & & & \\
\hline $\begin{array}{l}\text { 5. This care provider knows my medical history } \\
\text { very well }(n=399)\end{array}$ & 0.806 & & & & \\
\hline $\begin{array}{l}\text { 11. This care provider knows my familial } \\
\text { circumstances very well }(n=395)\end{array}$ & 0.746 & & & & \\
\hline $\begin{array}{l}\text { 8. This care provider remembers me very well } \\
\text { when he/she sees me }(n=404)\end{array}$ & 0.743 & & & $\mathrm{x}$ & $\begin{array}{l}\text { Relatively high ceiling effect and } \\
\text { relatively low SD }\end{array}$ \\
\hline $\begin{array}{l}\text { 4. This care provider knows very well which } \\
\text { care I receive more }(n=400)\end{array}$ & 0.739 & & & $x$ & $\begin{array}{l}\text { Relatively high ceiling effect and } \\
\text { relatively low SD }\end{array}$ \\
\hline $\begin{array}{l}\text { 10. This care provider knows my relevant } \\
\text { medical data very well }(n=393)\end{array}$ & 0.726 & 0.427 & & $\mathrm{x}$ & $\begin{array}{l}\text { High loading on two factors and } \\
\text { relatively high missing rate }\end{array}$ \\
\hline $\begin{array}{l}\text { 12. This care provider knows my daily } \\
\text { activities very well }(n=391)\end{array}$ & 0.702 & & & & \\
\hline $\begin{array}{l}\text { 7. This care provider always knows very well } \\
\text { what he/she did previously }(n=399)\end{array}$ & 0.629 & & & & \\
\hline \multicolumn{6}{|l|}{$\begin{array}{l}\text { Personal continuity: care provider shows } \\
\text { commitment }\end{array}$} \\
\hline $\begin{array}{l}\text { 14. This care provider contacts me if it is } \\
\text { needed, I do not have to ask }(n=379)\end{array}$ & & 0.887 & & & \\
\hline $\begin{array}{l}\text { 16. This care provider keeps in contact } \\
\text { sufficiently when I see other care } \\
\text { providers }(n=363)\end{array}$ & & 0.791 & & & \\
\hline $\begin{array}{l}\text { 15. This care provider knows very well what } \\
\text { I believe is important in my care }(n=392)\end{array}$ & 0.495 & 0.705 & & & \\
\hline \multicolumn{6}{|c|}{ PCA on items $17,18,19,21,22,23,24,26,27,28,29,30$} \\
\hline \multicolumn{6}{|c|}{ Team and cross-boundary continuity } \\
\hline $\begin{array}{l}\text { 23. These care providers work together very } \\
\text { well }(n=301)\end{array}$ & & & 0.901 & & \\
\hline $\begin{array}{l}\text { 22. These care providers are very well } \\
\text { informed of each other }(n=286)\end{array}$ & & & 0.884 & $x$ & Relatively high missing rate \\
\hline $\begin{array}{l}\text { 19. The care of these care providers is very } \\
\text { well adapted to each other }(n=302)\end{array}$ & & & 0.880 & $x$ & $\begin{array}{l}\text { Highly correlated to item } 18(0.808) \\
\text { but more difficult to answer }\end{array}$ \\
\hline $\begin{array}{l}\text { 26. These care providers are very involved } \\
\text { in each other's care }(n=281)\end{array}$ & & & 0.876 & $x$ & Relatively high missing rate \\
\hline $\begin{array}{l}\text { 17. These care providers communicate very } \\
\text { well with each other }(n=303)\end{array}$ & & & 0.867 & $\mathrm{x}$ & $\begin{array}{l}\text { Highly correlated to item } 18(0.860) \\
\text { but more difficult to answer }\end{array}$ \\
\hline $\begin{array}{l}\text { 18. These care providers transfer information } \\
\text { very well to each other }(n=313)\end{array}$ & & & 0.850 & & \\
\hline $\begin{array}{l}27 . \text { The care of these care providers is very } \\
\text { well connected }(n=316)\end{array}$ & & & 0.849 & & \\
\hline $\begin{array}{l}\text { 29. These care providers know the results of } \\
\text { each other's medical examination very well } \\
(n=292)\end{array}$ & & & 0.849 & $\mathrm{x}$ & $\begin{array}{l}\text { Content is comparable to item } 19, \\
\text { but with higher missing rate } \\
\text { and lower SD }\end{array}$ \\
\hline $\begin{array}{l}28 \text {. These care providers always know very well } \\
\text { from each other what they do }(n=284)\end{array}$ & & & 0.848 & & \\
\hline $\begin{array}{l}\text { 24. These care providers always agree about } \\
\text { the care I receive }(n=274)\end{array}$ & & & 0.819 & $x$ & $\begin{array}{l}\text { Relatively low loading on factor, } \\
\text { relatively low } \mathrm{SD} \text {, relatively } \\
\text { high missing rate }\end{array}$ \\
\hline $\begin{array}{l}\text { 30. These care providers know very well who } \\
\text { else is concerned in my care }(n=282)\end{array}$ & & & 0.796 & $x$ & $\begin{array}{l}\text { Decreases the interpretability } \\
\text { of the factor, relatively high } \\
\text { missing rate, relatively low } \\
\text { loading on factor }\end{array}$ \\
\hline
\end{tabular}


Uijen, A.A., Schellevis, F.G., Bosch, W.J.H.M. van den, Mokkink, H.G.A., Weel, C. van, Schers, H.J. Nijmegen Continuity Questionnaire: development and testing of a questionnaire that measures continuity of care. Journal of Clinical Epidemiology: 2011, 64(12), 1391-1399

Table 3. Continued

\begin{tabular}{|c|c|c|c|c|c|}
\hline \multicolumn{4}{|l|}{ PCA } & \multirow[b]{4}{*}{$\begin{array}{c}\text { Excluded } \\
\text { items }\end{array}$} & \multirow[b]{4}{*}{ Reasons for exclusion } \\
\hline & \multicolumn{3}{|c|}{ Factor loadings } & & \\
\hline & Factor 1 & Factor 2 & Factor 3 & & \\
\hline Type of continuity & $\begin{array}{c}\text { Eigenvalue: } \\
7.304\end{array}$ & $\begin{array}{c}\text { Eigenvalue: } \\
1.130\end{array}$ & $\begin{array}{l}\text { Eigenvalue: } \\
8.617\end{array}$ & & \\
\hline $\begin{array}{l}\text { 21. The care between these care providers } \\
\text { goes very smoothly }(n=299)\end{array}$ & & & 0.739 & $x$ & $\begin{array}{l}\text { Relatively low SD, relatively } \\
\text { high missing rate, relatively } \\
\text { low loading on factor }\end{array}$ \\
\hline
\end{tabular}

Values $<0.40$ are suppressed. Missing values were excluded pairwise.

Abbreviations: PCA, principal component analysis; SD, standard deviation.

Table 4. Summary statistics of the subscales of the NCQ

\begin{tabular}{|c|c|c|c|}
\hline Statistics & $\begin{array}{l}\text { Personal continuity: care } \\
\text { provider knows me }\end{array}$ & $\begin{array}{l}\text { Personal continuity: care } \\
\text { provider shows commitment }\end{array}$ & $\begin{array}{l}\text { Team and cross-boundary } \\
\text { continuity }\end{array}$ \\
\hline Number of items & 5 & 3 & 4 \\
\hline \multicolumn{4}{|l|}{ Mean interitem correlation (range) } \\
\hline Most important care provider in general practice & $0.58(0.17)(n=233)$ & $0.61(0.16)(n=219)$ & - \\
\hline $\begin{array}{l}\text { Most important care provider in hospital/outpatient } \\
\text { department }\end{array}$ & $0.58(0.26)(n=133)$ & $0.66(0.14)(n=124)$ & - \\
\hline $\begin{array}{l}\text { Collaboration between care providers within general } \\
\text { practice }\end{array}$ & - & - & $0.67(0.16)(n=117)$ \\
\hline $\begin{array}{l}\text { Collaboration between care providers within hospital/ } \\
\text { outpatient department }\end{array}$ & - & - & $0.71(0.25)(n=52)$ \\
\hline $\begin{array}{l}\text { Collaboration between general practice and hospital/ } \\
\text { outpatient department }\end{array}$ & - & - & $0.67(0.15)(n=98)$ \\
\hline \multicolumn{4}{|l|}{ Cronbach $\alpha$} \\
\hline Most important care provider in general practice & 0.87 & 0.82 & - \\
\hline $\begin{array}{l}\text { Most important care provider in hospital/outpatient } \\
\text { department }\end{array}$ & 0.87 & 0.85 & - \\
\hline $\begin{array}{l}\text { Collaboration between care providers within general } \\
\text { practice }\end{array}$ & - & - & 0.89 \\
\hline $\begin{array}{l}\text { Collaboration between care providers within hospital/ } \\
\text { outpatient department }\end{array}$ & - & - & 0.89 \\
\hline $\begin{array}{l}\text { Collaboration between general practice and hospital/ } \\
\text { outpatient department }\end{array}$ & - & - & 0.89 \\
\hline Potential range of scores & $1-5$ & $1-5$ & $1-5$ \\
\hline \multicolumn{4}{|l|}{ Mean of patient scores (SD) } \\
\hline Most important care provider in general practice & $3.48(0.77)$ & $3.32(0.82)$ & - \\
\hline $\begin{array}{l}\text { Most important care provider in hospital/outpatient } \\
\text { department }\end{array}$ & $2.90(0.78)$ & $3.12(0.89)$ & - \\
\hline $\begin{array}{l}\text { Collaboration between care providers within general } \\
\text { practice }\end{array}$ & - & - & $3.76(0.59)$ \\
\hline $\begin{array}{l}\text { Collaboration between care providers within hospital/ } \\
\text { outpatient department }\end{array}$ & - & - & $3.37(0.81)$ \\
\hline $\begin{array}{l}\text { Collaboration between general practice and hospital/ } \\
\text { outpatient department }\end{array}$ & - & - & $3.47(0.71)$ \\
\hline
\end{tabular}

Missing values were excluded listwise.

Abbreviations: NCQ, Nijmegen Continuity Questionnaire; SD, standard deviation. 